\title{
POST-WAR PROBLEMS OF THE LUMBER INDUSTRY OF EASTERN CANADA
}

\author{
BY E. S. FeLLOWS,
}

\author{
Maritime Lumber Bureau, Amherst, N.S.
}

W HAT is our conception of "reconstruction?" Probably each of us has his own ideas on this subject, and a dictionary will not help much in securing precise agreement. It is, therefore, unwise for anyone to write or speak on the problems involved without stating what he understands by the process of "reconstruction." Here, as briefly as possible, is my impres. sion: Reconstruction is a purposeful re-designing of an industry or service to promote human betterment. It does not necessarily involve tearing down or even starting afresh, but it does involve far more than patching and bolstering worn out practices. Reconstruction starts with what we have, but proceeds in a new direction, and this direction must conform to changed requirements and changed thought. In the case of an industry, the welfare of all those interested must be considered, which means worker, employers, customers, and the community at large.

If my definition finds general acceptance, then the first thing we must know and understand is what we have to work with, for there is where reconstruction begins. Next we must agree on what we wish to achieve. Finally, we must design the bridge that is to span the gap between what we have and what we want; and there, of course, we shall find the problems we set out to discuss.

Before launching into a discussion of those matters which seem to call for reconstruction it would be as well to paint a hasty picture of the industry we are considering. This will serve as a back-drop, as it were, for the various scenes to be presented. Unfortunately, limitations of time and space dictate that picture be something of a caricature, perhaps unduly accentuating the prominent features, but this will be sufficient background for a short paper of this kind.

The lumber industry of Eastern Canada may be roughly divided into three sections. First, the spruce-hemlock-jack pine group, which is the dominant element so far as total volume and total value of products, and number of producing units are concerned; it is the "proletariate" of the industry. The second section is the hardwood group, chiefly birch and maple, which occupies an intermediate position-"the middle class" element of the industry. Finally, there is the white pine-red pine group, which is relatively concentrated geographically, mechanically and in terms of output per plant. It has a relatively small total volume of production, as compared with spruce, but a high unit value. This is the "aristocracy" of the industry.

Throughout the whole region the industry operates on both public and freehold properties, but probably the larger portion of the cut, of all species, 
comes from Crown lands. Throughout the region, too, the majority of the loggers and a substantial proportion of mill workers, are drawn from farms during the off-season. They have learned their trades the hard and inefficient way-by trial and error, by sweat, accidents, low income, and discomfort.

The whole industry is notoriously wasteful in the sense that it has failed to develop markets for its by-products. The whole industry has certain obstacles in common, namely, unpredictable hazards, uncoordinated taxation, and a very long manufacturing process entailing large inventories of raw material and semi-finished products. The latter is a particularly undesirable condition in the case of a product so dependent on the world market. The industry as a whole relies heavily upon foreign markets with all their intricacies and hazards. It has, with few exceptions, retained the manufacturing techniques of thirty years ago, save in the field of forest operations. It has common competitors - the producers of other structural products. And, finally, it conducts its business through the same system of wholesalers, retailers, and brokers, who are the storekeepers and commercial travellers of the industrial "society" we have used by way of illustration.

All these attributes the entire lumber industry of Eastern Canada shares in common, but beyond these each section of the industry has its own problems which are the result of its own particular practices and stage of development. These, too, must be taken into account in any planned reconstruction and should, therefore, be briefly outlined.

\section{The Spruce-Hemlock-Jack Pine Section}

In this section of the industry small mills with a daily output of eight to twenty thousand feet predominate in numbers and also in total volume of production, although there are many much larger units as well. In the case of the smallest of these mills, the owner may be a farmer. In the vast majority the owner himself, besides directing the operation and looking after the office work, takes on some job in the mill, often the sawing or tallying. Under these conditions it is not to be expected that the proprietor will be well in formed on the complexities of the lumber market or the finer technicalities in lumber manufacture. Because of his comparatively large investment in inventory the small operator is very rarely financially independent. His aim, therefore, is to produce at the lowest cost and to sell at the first opportunity, which often means that he virtually sells before he produces. This in turn generally means that he uses poor logging practices and poor equipment, provides poor living and working conditions for his employees, pays low wages, takes little care of, or pride in, his product, and has little interest in what becomes of his lumber after he has sold it or what value is placed on it by the ultimate consumer.

Under these conditions, the quality of manufacture, though not necessarily the quality of the wood, is of the poorest and the operator ordinarily has no choice but to accept a rock-bottom price for his product. Consequently he is never able to get out of the rut he is in; a low-price product can do nothing but perpetuate itself and all the ills it entails-low profits, low wages, and a low return or even a net loss to the community at large. 
Of course a substantial part of the industry operates on a much higher level, but it is perpetually held back by the less efficient majority; truly a case of the tail wagging the dog. Therefore, when it is suggested that the lot of the small proprietor should be improved, the suggestion is not made solely for his benefit. No element in the industry can attain its maximum development or welfare until the drag exerted by the lower strata has been removed. In other words, any improvement in the practices of the small producer will bring corresponding advantages to his larger colleagues in the trade. In a very real sense the efficient producer is now competing against the less able in his own business. This kind of competition benefits nobody and obviously calls for "reconstruction."

\section{The Hardwood Section}

This element of the lumber industry differs from the spruce section chiefly in the matter of degree but it has one or two distinct advantages not yet enjoyed by the latter. The most important of these advantages is the possession of a set of standardized grades recognized throughout the continent and even beyond. These grades are constantly kept up-to-date and are well enforced. The use of these grades has developed recognized price differentials based on quality and they have tended to stabilize the hardwood market, even for those producers who do not themselves use the grades. The natural desire of every hardwood operator selling on grade is to get the greatest possible proportion of his cut into the higher-price brackets. He, therefore, takes a keen interest in production methods and improves the manufacture of his product. He also tends to select his raw materials more carefully, which in turn creates differences in stumpage values that are desirable in any approach to the development of better forest management. In one other aspect the hardwood trade is essentially better off than the spruce section. It has been able to find more markets for products other than lumber, notably ties, dimension stock, and flooring. These products offer an opportunity to reduce the volume of material wasted and provide an alternative market for the lower-quality wood.

It is not suggested that, because the hardwood operators of Eastern Canada have made substantial progress in the past twenty years or so, they have reached perfection and have no more problems and no need of "reconstruction." That is far from being the case. They have only started and so, as has been said, their chief handicaps differ only in degree from those of the spruce trade. But what progress they have made is a clear enough indication of what more they can accomplish under a well planned program and what the spruce industry can expect if it adopts similar principles.

\section{The Pine Section}

In the main, this part of the lumber industry of Eastern Canada differs materially from the others. In the first place it is dominated, so far as volume of production is concerned, by large producers. The industry is geographically compact, relatively efficient from a mechanical point of view 
and highly organized as a group. It has brought the practice of grading to a high stage of development with great advantage to itself and to its clientele. The management of the mills is usually in the hands of men who have the time and the opportunity to study the market, production methods and matters of policy.

This section of the industry pays somewhat higher wages than others, requires men of higher skill, provides better working and living conditionsgenerally speaking -and receives much higher prices for its products. It is not hampered, as are small producers, in financing current operations, and is, therefore, not under the same pressure to sell at sacrifice prices or on unfavourable conditions.

The fact that the pine industry has reached a higher stage of develop. ment than the rest of the lumber trade of the region is not wholly, or even chiefly, the result of self-help and organization, although these have played an important part. Geography and nature have, in the main, shaped the course of industry. Likewise, the present relatively high level of welfare in the pine section does not mean that it has no problems to face but only that the problems are, for the most part, different from those facing the spruce and hardwood producers.

Nature, which did more than anything else to make the pine industry what it is, is withdrawing some of its support, and the pine producers are finding it increasingly difficult to procure logs of the same size and quality that made the species famous. It would seem, therefore, that within a comparatively few years the production and marketing of pine lumber will be undergoing a transition; a transition which may well involve changes in plants, outlets, and operating techniques in general.

This description of the various sections of the lumber trade is, of course, very general. Actually there is much over-lapping. Each section has its big and little producers, its good and poor quality cuts, its good and poor working conditions. However, from what has been said of the outstanding problems it may be deduced that certain fundamental policies should be pursued in any reconstruction program. Among the more important of these are:

1. The development of a better informed and more unified industry.

2. The fostering of higher and more stable sales-values;

3. The development of a higher type of worker;

4. The promotion of lower unit costs in relation to sales-values;

5. The adjustment of regulations and taxation to industrial needs; and,

6. Assurance of a continuing supply of raw materials.

Some of the ways in which these policies may be implemented are sug. gested in the remainder of this paper.

\section{BETTER INFORMED AND MORE UNIFIED INDUSTRY}

This is probably the most urgent need of all, because without information and united action the other objectives will be difficult, if not impossible, to achieve. It is important to note also that the informed industry is necessary before united action can be brought about because a desire to unite in action cannot be born in an atmosphere where there is no understanding of the 
need to unite. This suggests a relatively new approach to the matter of recruiting membership in trade associations. An uninformed individual can not be sincerely interested in joining a trade association, and an insincere member is a liability. There must, therefore, be a policy of distributing information to uninformed persons without the need of these individuals first belonging to an organization or paying fees. An interesting experiment in this connection has been going on for four years under the sponsorship of the Maritime Lumber Bureau. Few who are familiar with this experiment will deny its success or its logic. Furthermore, that section of the industry which is well informed cannot translate its knowledge and skill into action to the fullest extent as long as there is any substantial body of uninformed individuals engaged in the industry impeding progress. It is, therefore, in the interests of the best producers that the greatest attention should be paid to the less capable on'es.

The dissemination of information on various aspects of the lumber trade can be accomplished in several ways: by trade associations carrying a certain number of non-members on their rolls, by extension activities of universities, by government co-operation through the medium of district foresters or rangers, and possibly through radio programs, public meetings, and demonstrations.

Once an informed industry has been brought into being, it will be comparatively easy to bring about unity of action and to create strong, publicspirited, energetic trade associations.

\section{Higher and More Stable Sales-Values}

By higher sales values is meant, not an arbitrary increase in prices but a closer relationship between quality and value. Higher values will not by themselves bring any fundamental advantages except a larger profit to the seller but this is only part of what is sought. They will, however, form an essential pre-requisite for other gains by providing an incentive for improved production now lacking or inadequately developed. This in turn should benefit all whose welfare is directly or indirectly bound up with the fortunes of the lumber trade.

The first step in obtaining more equitable prices is the establishment and propagation of standardized grades. The spruce section is the only one which is not yet following this practice but, through the activities of the Maritime Lumber Bureau, this fault is being corrected. But, although good progress is being made, both the spruce and hardwood industries and, for that matter, some elements of the pine section should press this policy more vigorously.

The establishment of standard grades opens new market possibilities. Grade-uses can be worked out and the better quality lumber can be directed into the appropriate markets which pay prices commensurate with their special needs. When a product is tailored to the consumer's requirements market research and trade promotion activities become fruitful, but experience has shown that only very limited results can be achieved by trying to "push" sales of ungraded lumber. 
There are, then, three main steps in seeking better prices: first, the segre. gation of products according to quality; second, a search for the most profitable and most stable market for each quality produced and third, an improvement in manufacturing techniques with a view to obtaining higher proportions of the better grades. To these basic needs it may also be necessary to add some revisions of existing methods of distribution so as to ensure the movement of lumber into the most desirable markets.

Those things which raise the status and value of lumber also tend to stabil. ize market conditions and to eliminate many of those sales-practices which are injurious to the trade as a whole. In order to achieve the most satisfactory degree of stability, however, one further thing is needed, namely, the widest possible distribution of information on all matters pertaining to price movements and current and prospective conditions in the trade.

\section{BETTER TYPe OF WORKER}

More skillful and more contented employees are needed as much for the good of the industry as for the sake of the individual workers themselves. There has long been a tendency to consider that the only qualifications needed in a woods or sawmill worker are "a strong back and a weak mind." That philosophy has not brought outstanding success. To retain the best type of worker in the business we must make his occupation more attractive to him. Several ways of doing this suggest themselves, namely: (a) a higher level of peace-time wages; (b) better living and working conditions; (c) greater permanency of employment; and, (d) stimulation of interest in his occupation.

Little need be said on the subject of wages as it is fairly generally conceded that the pay of woods workers in Eastern Canada is deplorably low. Only those who are firmly convinced that lumber must be a low-value, low-quality product deny that wages can be raised. Working conditions also have been much discussed. A few old-timers contend that the lumber-jack of fifty years ago was healthier and more contented than his successor and, therefore, we should not "pamper" the woods worker of today. Perhaps this contention is correct, but it does not, and will not, impress the worker. To take such an attitude is, therefore, unrealistic in the extreme. The trend must be toward less back-breaking work, more comfortable working and living conditions, more opportunity for recreation and, last but not least, less isolation and monotony.

It is probably necessary, and perhaps desirable, that a large part of the labor required by the lumber industry should be recruited seasonally from farms. Nevertheless, increasing emphasis should be placed on the need of giving permanency to as many jobs as possible. There are many who believe that it would be better to employ a smaller number of men over a longer period than to continue the present practice. This theory has many interesting possibilities which cannot be discussed here.

The stimulation of a man's interest in his job is something which has not been given adequate attention in the lumber industry. This point is developed further in the next section of this paper, but for the moment its 
importance from the point of view of morale may be examined. An untrain. ed woods worker is a drifter. He has little interest in his work beyond the income it brings-and that is small. He lacks initiative, has no special status, and usually has no special loyalty to his temporary employer. His chief ambition is to get into some more remunerative work. His whole environment is such that he is unstable and often of low productive value. The training of men to give them special skills and offering them openings for permanent employment, more chance to show initiative, and hence more opportunities for advancement, all hold great possibilities.

The trends of to-day make it increasingly necessary for an employer to get inside the minds of his employees and to put himself in their position if he is to get the most out of them. Failure of lumbermen to do this to a greater extent may mean that the lumber industry will attract only those workers who are too incompetent, too lazy, too old, or too unstable to find employment elsewhere. Under such conditions the industry could not possibly be vigorous, healthy, or progressive.

\section{Lower Unit Costs in Relation to Values}

Having advocated a higher level of wages some suggestion should be made as to how this can be accomplished. Of course, the first step and the one which can be most quickly taken, is to raise the value of the products of the industry. The second step is to reduce the relative costs of production, chiefly by increasing the output per man. This is a long-term undertaking requiring considerable study.

The importance of training as an aid to morale has already been mentioned, but training is even more significant from the standpoint of costs. Although the worker should receive higher wages he must still be worthy of his hire, and he must, therefore, earn his higher wage through increased efficiency. Quite a number of experiments have already shown that the productivity of woods workers can be increased surprisingly by training them to make their work easier. The same is probably true of sawmill workers. Safety too can be promoted by education, and most lumbermen are well aware of the cost of accidents. In the light of present knowledge it does not seem too optimistic to expect that the productivity of the average worker in the lumber industry can be increased by at least ten per cent through training alone.

Something can also be done in the matter of equipment and methods both to increase output and to improve quality. Figures show that the mechanical power at the disposal of each sawmill worker in Eastern Canada has increased only very slightly since the last war and the output per worker has decreased very sharply in the same period. Simultaneously wages paid per unit of output have increased appreciably despite the fact that the level of wages throughout the region was lower before this war than at the end of the last war. There are several explanations for these conditions, and not all of them reflect upon the ability of the trade, but they are out of line with the general industrial trends. A thorough study of the mechanical 
needs of the industry would probably pay high dividends. The same might be said of the methods employed. Studies have already shown that the manhour production in a sawmill can be increased appreciably by systematizing and stream-lining techniques.

The burden of waste also weighs very heavily on lumber costs. This can be appreciated when one realizes that only one-third to one-half of the raw material entering a sawmill emerges in the form of lumber. No effort should be spared in reducing the proportion of by-products and in finding ways of making unavoidable by-products carry their own cost at least.

The cost of production is also influenced to a very great extent by the nature of the raw materials available and the capacity of the sawmill. It is common knowledge to all familiar with woods operations that many potential sawlogs are being diverted to other uses, chiefly pulp. The lumber and pulp industries are both important to our forest economy and we cannot allow them to compete with one another unnecessarily. That being the case attention should be given to integrating the two as soon as possible.

We should also try to discover the most economical capacity for saw. mills in the region. Both very large and very small sawmills tend to be uneconomic for various reasons. If we can arrive at a conclusion as to the design and capacity of an ideal sawmill for the region, we can probably devise means of organizing producers to make use of the most economical means of production.

\section{Adjustment of Regulations and Taxation}

Crown Land Timber Regulations are fairly generally admitted to be far from perfect. It is also conceded by most that it is impossible to lay down rules which will be universally just and workable and that the only fair way to control the use that is made of Crown Lands is through the preparation of working plans suited to each area. For some time to come, however, it will be necessary to continue to rely on general regulations and, therefore, some attempt should be made to improve them. The present practice is to frame such regulations in a purely negative spirit. That is to say, they consist entirely of lists of prohibitions and penalties. It is suggested that such a policy merely prevents forest operations from becoming intolerably bad, but does nothing to induce the operator to do better than to fulfil the minimum requirements; indeed, it sometimes actively dissuades him from doing more than he is compelled to do. Would it not be preferable to complement these prohibitions with encouragements and bonuses for those who do better than is required of them? There is, for example, no inducement for an operator to cut smaller tops or lower stumps than the law prescribes, yet these things could be done if they were made economically attractive. It is rightly asserted that good forest management will be practised 
if it can be shown to pay. Here is an opportunity for the largest woodlands owner-the Crown-to prove that assertion. Admittedly diffculties and dangers are involved in such a policy, but the benefits and the principles too are important.

The writer lays claim to no special knowledge of taxation problems, but it is quite plain that the lumber industry suffers from a multiplicity of taxes many of which do not bear any direct relation either to the value of the land or the timber or to the ability of the operator to pay them when due. This is not a plea for a general lowering of taxation, but only a suggestion that the whole system of taxing forest lands and forest products should be overhauled with a view to making it more equitable and more closely related to actual production, production possibilities and production costs.

\section{Assurance of Continuing Supply or Raw Materials}

This whole question is intimately associated with the broad implications of sound forest policy and forest management. These subjects have been frequently discussed from all angles and this Society has adopted its own comprehensive policy. Little more, the refore, need be said in a paper of this nature. One thing, however, should be stressed and that is the desirability of fostering a closer integration of the wood-using industries so that each may obtain raw material well suited to its needs. It is illogical, for example, to witness pulp mills going to considerable expense cutting large bolts into more suitable sizes while a short distance away sawmills are trying to make lumber out of pulpwood. Some plan must be worked out whereby logs can be exchanged between different industries so that all can operate at high efficiency.

Furthermore, in many cases the by-products of one plant will serve as a raw material for another. Generally speaking, the wood-chemical industries can use sticks of any size provided that they can be delivered at an economic price but sawmills, veneer plants, and producers of poles, ties and other structural products must have logs of a special character to meet their needs. To ignore this fact is to jeopardize the future of several industries we can ill afford to lose and which there is no need to lose.

There are, of course, many other problems which could not possibly be dealt with in a paper of this nature. As a matter of fact the solution of one set of problems will automatically produce another set. That is the essence of progress. However, the correction of the faults here discussed should provide adequate opportunity for the solution of most of the remaining problems. It should be emphasized that all conditions described in this paper were those obtaining before the war. Many of them are changed today but there is no reason to believe that the changes are any. thing but the temporary results of wartime conditions. 